\title{
Cone crusher in the cylindrical roller bearing contact analysis
}

\author{
Zhou Zhang ${ }^{1, a^{*}}$,Shuisheng Chen ${ }^{2, b}$, Yi Yang ${ }^{3, c}$ \\ ${ }^{1}$ Wuhan, Hubei university of technology of Hubei province institute of mechanical \\ engineering ,China \\ ${ }^{2}$ Wuhan, Hubei province of Hubei university of technology institute of mechanical engineering, \\ China \\ ${ }^{3}$ Wuhan, Hubei province of Hubei university of technology institute of mechanical engineering, \\ China \\ a1501864035@qq.com, b80466846@qq.com, '393388826@qq.com
}

Keywords: Cone crusher; Cylindrical roller bearing; The finite element analysis

Abstact: Stress analysis was carried out on the cone crusher, calculate the radial load of cylindrical roller bearing, good model will be built using solidworks software imported into the workbench in finite element analysis, get the cylindrical roller bearing displacement and equivalent stress distribution rule and the position of the roller stress concentration, for cylindrical roller bearings provide theoretical bas is for the structural optimization and design.

\section{The introduction}

Cone crusher is a widely used in metallurgy, construction, chemical industry such as heavy machinery equipment. It is the main material crushing to a certain degree of particles, and plays a key role in the corresponding production process. The volume of a cone crusher is compared commonly big, heavy quality, so it is the inside of the sliding bearing and rolling bearing requires special customization. Based on the Terex's a cone crusher, for example, the structure of crusher with China now there is a big difference in the mainstream of the crusher structure, it mainly adopts rolling bearing instead of sliding bearing. While rolling bearing the heat dissipation effect is better than sliding bearing, but the sliding bearing worse than the bearing capacity of the rolling bearing, this needs us to analyze the mechanical properties of rolling bearing.

\section{Cylindrical roller bearing force analysis}

Under normal working state, the size of the force of cone crusher are influenced by the physical and chemical properties such as ore, hardness, mechanical properties, breaking method and ore crushing cavity in the distribution and so on many factors. If using a theoretical formula to calculate the crushing force is a difficult, so using by crusher work normally when the hydraulic cylinder pressure to calculate crushing force. Crushing force calculation formula as shown in formula 1.All parameters of the cone crusher are shown in table 1. To break into the various parameters in table 1 generation force calculation formula, to calculate maximum crushing force of cone crusher. Due to the crushing force is perpendicular to the moving cone lining board, we can undertake decomposition for crushing the biggest force $\mathrm{F}$, get along the moving cone axis direction component 
itself F2, and the component in the direction of perpendicular to the axis of the moving cone itself $\mathrm{F} 1, \mathrm{~F} 1$ is cylindrical roller bearings are one of the biggest radial force.

Table $1 \quad$ Cone crusher parameter table

\begin{tabular}{|c|c|c|c|c|c|}
\hline $\mathrm{D} 1(\mathrm{~mm})$ & $\mathrm{P}(\mathrm{MPa})$ & $\mathrm{n}($ quantity) & $\boldsymbol{\alpha}$ (degree) & $\boldsymbol{\gamma}$ (degree) & $\mathrm{G}(\mathrm{Kg})$ \\
\hline 1365 & 20 & 8 & 40 & 1.67 & 3236 \\
\hline
\end{tabular}

The biggest crushing force $\quad F=\frac{0.78 B_{1}{ }^{2} n P-G}{\operatorname{COS}(a-g)}$

The formula 1

D1: The hydraulic cylinder piston diameter $(\mathrm{mm})$

P: Normal crushing ore, the unit of hydraulic pressure

$\left(\mathrm{N} / \mathrm{m}^{2}\right)$

$\mathrm{n}$ : The number of hydraulic cylinder

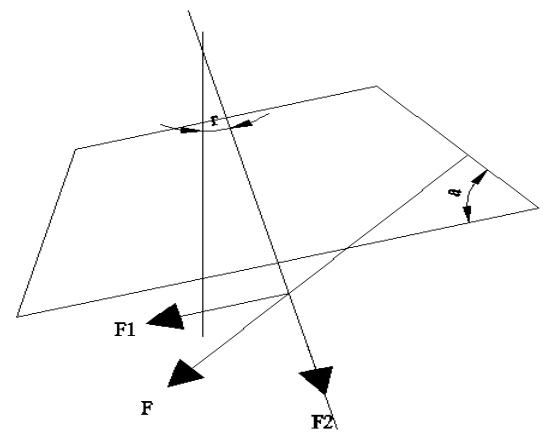

$\alpha$ : Dynamic cone Angle on the conical bottom(degree)

$\mathrm{Y}:$ Precession Angle (degree)

$\mathrm{G}$ : The moving cone weight $(\mathrm{N})$

Figure 1 The force diagram of The moving cone

Cylindrical roller bearing radial force $\quad F 1=F \cos \left(90^{\circ}-a\right)$

The numerical generation into the formula, cylindrical roller bearing radial force $\quad F 1 \approx 5150 \mathrm{KN}$

\section{Statics analysis}

\section{Modeling and meshing}

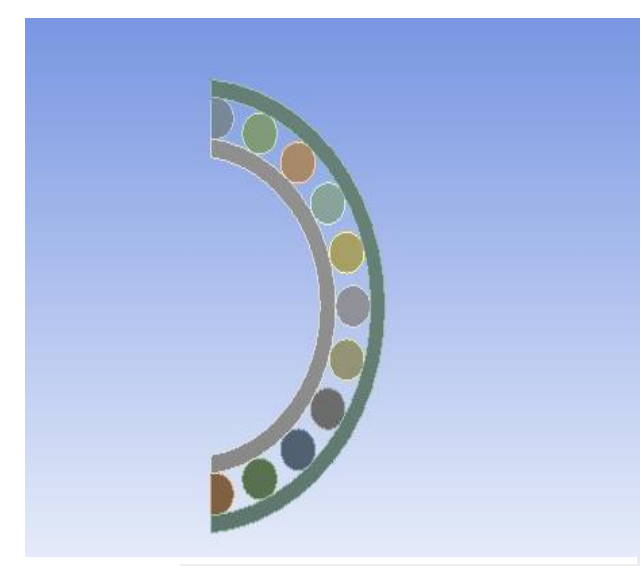

Figure 2 Cylindrical roller bearing 3D model diagram
Based on the structure parameters of cylindrical roller bearing, the use of $3 \mathrm{D}$ drawing software SOLIDWORKS draw the corresponding 3D model, and the model of the round corner, chamfer to simplify processing, in order to and analysis, not considering the influence of the cage. Bearing structure parameters are shown in table 2. A model of a cylindrical roller bearing as shown in figure 2. Bearing structure parameters are shown in table 2.

3D model of cylindrical roller bearing imported into the workbench software. Due to the cylindrical roller bearing in the work only half a circle roller under the extrusion of radial force, so only $1 / 2$ statics analysis of the model. Rolling body, inside and outside the circle of grid is set to the system default values, the automatic classification method is adopted to meshing of bearing, meshing, a total of 1766 units and 10888 nodes. 
Cylindrical roller bearing parameter table

\begin{tabular}{|c|c|c|c|c|c|c|c|c|}
\hline $\begin{array}{l}\text { Outer } \\
\text { diameter } \\
\text { of the } \\
\text { bearing } \\
\text { outer } \\
\text { ring } \\
\text { D1 }(\mathrm{mm})\end{array}$ & $\begin{array}{l}\text { The } \\
\text { inner } \\
\text { diameter } \\
\text { of the } \\
\text { bearing } \\
\text { outer } \\
\text { ring } \\
\text { D2 }(\mathrm{mm})\end{array}$ & $\begin{array}{l}\text { The } \\
\text { height } \\
\text { of the } \\
\text { bearing } \\
\text { outer } \\
\text { ring } \\
\mathrm{H}(\mathrm{mm})\end{array}$ & $\begin{array}{l}\text { Outer } \\
\text { diameter } \\
\text { of the } \\
\text { bearing } \\
\text { inner } \\
\text { ring } \\
\text { d1 }(\mathrm{mm})\end{array}$ & $\begin{array}{l}\text { The } \\
\text { inner } \\
\text { diameter } \\
\text { of the } \\
\text { bearing } \\
\text { inner } \\
\text { ring } \\
\mathrm{d} 2(\mathrm{~mm})\end{array}$ & $\begin{array}{l}\text { The } \\
\text { height } \\
\text { of the } \\
\text { bearing } \\
\text { inner } \\
\text { ring } \\
\mathrm{H}(\mathrm{mm})\end{array}$ & $\begin{array}{l}\text { The } \\
\text { diameter } \\
\text { of the } \\
\text { roller } \\
\mathrm{d}(\mathrm{mm})\end{array}$ & $\begin{array}{l}\text { The } \\
\text { height } \\
\text { of the } \\
\text { roller } \\
\text { H } \\
(\mathrm{mm})\end{array}$ & $\begin{array}{c}\text { The } \\
\text { number of } \\
\text { roller }\end{array}$ \\
\hline 550 & 508 & 260 & 408 & 363 & 260 & 50 & 240 & 22 \\
\hline
\end{tabular}

\section{Contact to set up}

Many body parts in side - to set up the contact with the surface contact. Contact to set has the following several principles: (1) the convex to concave/plane, the convex should be defined as interface;(2) if the two contact surfaces, a contact surface grid is thinner, and the other a grid is coarser, define the grid is fine for the contact area;(3) the two contact surfaces, a contact surface is soft, another is hard, the softer the surface is defined as interface;(4) if the two contact surfaces, one of the attached entity unit is advanced unit, and the other a city with low order, you should put the high order of the corresponding surface is defined as the interface that entity;(5) of the two contact surfaces, if a face than another face, such as a face surrounded the another side, the bedding face is defined as the target surface. According to the contact situation of cylindrical roller bearing, cylindrical roller bearing outer ring and inner ring is defined as the target surface, cylindrical roller is defined as the contact area, set up 22 to contact, contact type for frictionless contact, choose the Augmented Lagrange, normal stiffness coefficient is set to 1 .

\section{Constraints and the applied load}

According to the actual working condition of bearing, would impose a fixed constraint of bearing outer ring, roller of circumferential displacement constraint, and setting roller with inside and outside the circle for frictionless constraint, constraint within the bearing inner ring surface $\mathrm{Y}$ and $\mathrm{Z}$ to the displacement.. Places a load within the bearing inner ring surface of F1, and solving.

\section{Results analysis}

Cylindrical roller bearing is obtained by the workbench post-processing analysis result, the total displacement nephogram (as shown in figure 3), the total equivalent stress nephogram (as shown in figure 4) and the maximum pressure roller pressure contours (as shown in figure 5).

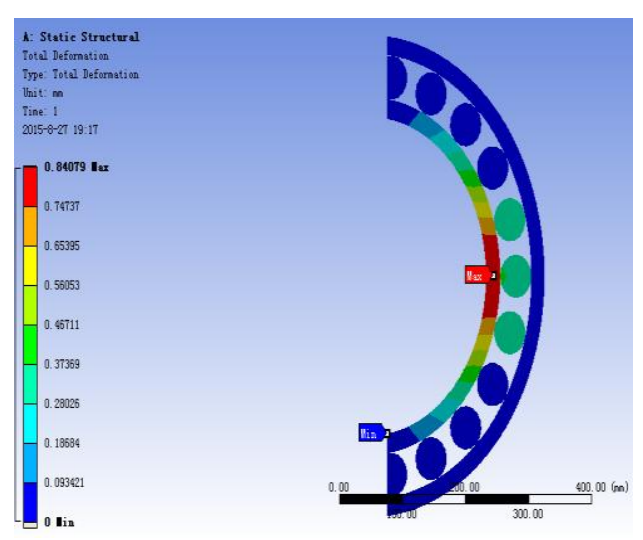

Figure 3 The displacement figure
We can see from figure 3, cylindrical roller bearing under radial load when the change of the total displacemen. The maximal displacement occurred in cylindrical roller bearing inner ring contact with Max radial force of the roller, the biggest total displacement $\mathrm{DMX}=0.84079 \mathrm{~mm}$. We can see from the diagram of the roller displacement with symmetry, in the direction of the radial force on both sides mutually symmetrical cylindrical roller bearing displacement change is consistent, the cylindrical roller bearing is verified by the radial force, displacement into symmetric distribution law. 


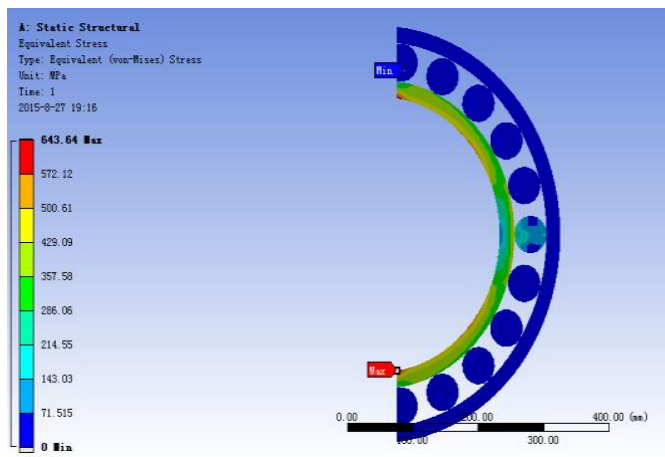

Figure 4(a) Equivalent stress figure

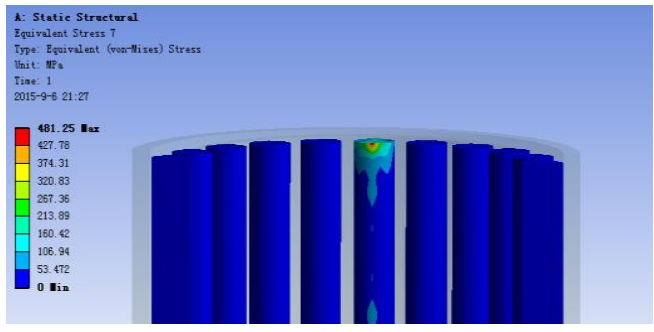

Figure 4(b) The largest stress of the roller stress diagram

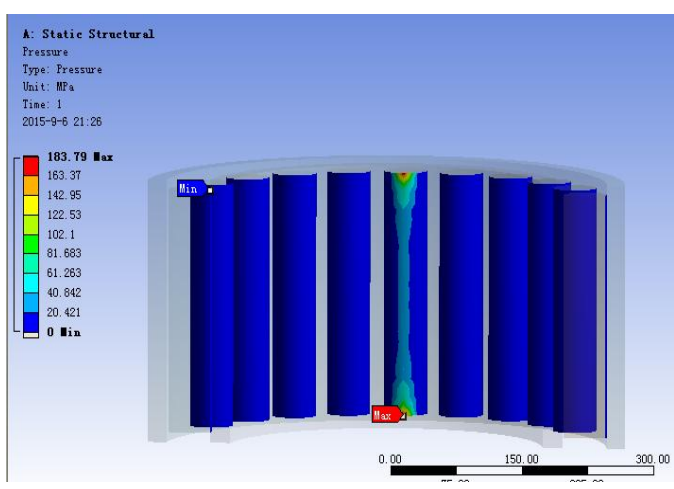

Figure 5 The largest stress of roller pressure figure

By figure 4 (a) (b), the larger the contact stress in cylindrical roller contact with the inner and outer ring, and the maximum contact stress in the cylindrical roller the bottom and the top contact with the inner and outer circle, and decreases in both sides. This illustrates the roller in contact with the inside and outside the circle is the relative concentration of stress. But the maximum stress occurred in the bearing inner ring of the neutral plane with radial force is vertical at both ends, this is because at this point they are produced by the radial force of tension stress.

By figure 5 largest stress of roller pressure contours, the cylindrical roller bear radial load when the maximum stress occurs at the top of the roller and the bottom respectively with cylindrical roller bearing inner ring contact position, maximum pressure is $183.79 \mathrm{MPa}$., and in the middle section of the roller pressure only 20.421 $\mathrm{MPa}$. Roller pressure on the top and bottom into symmetric distribution, respectively from the top and the bottom to the middle step gradually decreases, and the biggest contact area in the top and the bottom part of the cylindrical roller bearing, and to the middle period of gradually decreases, and the middle section of the contact area of approximate rectangle.

\section{Summary}

By the workbench statics analysis of the cylindrical roller bearing, can be intuitive show that bearing displacement and equivalent stress are symmetrical distribution, effective understanding of the various parts of the contact stress and strain and cloud image size, know the position of the roller stress concentration, to provide the basis for the optimization and design of the bearing structure.

\section{Reference}

[1] Junling Wang,Xiang Zhen,Huan Wu.[J]. Journal of yangzhou university, 2012, 15 (2): 43-46.

[2] Gang Dong,XiuMing Fan, Yi Zhang. Based on the theory of laminated crushing cone crusher crushing force analysis and kinematics research[J]. Journal of mechanical engineering, 2010,46 (17): $160-164$.

[3] Wei Wang. Cone crusher wear-resistant cavity type optimization design[D].Liaoning: Liaoning university of science and technology,2012.

[4] Sheng $\mathrm{Wu}$. Based on the rolling bearing contact finite element analysis of the problem 
[D]. Inner Mongolia: Inner Mongolia university of technology,2007.

[5] Ling Wang,FengLing,Chang. YuGui Tang. Based on the finite element analysis of ANSYS deep groove ball bearing[J], 2012 (7): 1053-1055. 